\title{
STRESS DROP AS A RESULT OF SPLITTING, BRITTLE AND TRANSITIONAL FAULTING OF ROCK SAMPLES IN UNIAXIAL AND TRIAXIAL COMPRESSION TESTS
}

\author{
JERZY CIEŚLIK \\ AGH University of Science and Technology, Department of Geomechanics, Civil Engineering and Geotechnics, \\ e-mail: jerzy.cieslik@agh.edu.pl
}

\begin{abstract}
Rock samples can behave brittle, transitional or ductile depending on test pressure, rate of loading and temperature. Axial stiffness and its changes, relative and absolute dilatancy, yield, and fracture thresholds, residual strength are strongly pressure dependent. In this paper the stress drop as an effect of rock sample strength loss due to failure was analyzed. Uniaxial and triaxial experiments on three types of rock were performed to investigate the stress drop phenomenon. The paper first introduces short background on rock behavior and parameters defining a failure process under uniaxial and triaxial loading conditions. Stress drop data collected with experiments are analyzed and its pressure dependence phenomenon is described. Two methods for evaluation of stress drop value are presented.
\end{abstract}

Key words: laboratory investigations, stress drop, triaxial compression

\section{INTRODUCTION}

In the case of underground construction when it is possible that failure may occur, (for example, mining pillar, working roof or tunnel walls), the energy dissipated due to failure is a key factor for underground workings stability and support design. Stress drop phenomenon as an effect of rock strength loss is directly related to energy dissipated due to failure. It can be analyzed by laboratory investigation on intact rock samples in conventional and true triaxial compression tests (Ismail and Murrell [10], Mogi [16], Kwaśniewski [13]), on saw cut samples in conventional triaxial tests and biaxial tests, double shear tests and conventional shear tests (Mogi [16]). The experiments conducted on rock samples with a cut plane in biaxial tests and double shear tests usually are performed for rock friction, sliding and frictional stability analysis (Jaeger and Cook [11], Paterson [18], Byerlee [3]). Stick-slip phenomenon analyzed with this kind of tests has been studied by a number of researches (Byerlee and Brace [4], Dieterich [7]) and proposed as the mechanism of earthquakes (Brace and Byerlee 1966).

In this paper, the effect of confining pressure on the stress drop following the intact rock samples failure in conventional triaxial compression tests conditions is investigated. Three different rocks, Wustenzeller sandstone, sandstone from ZG Rudna cooper mine ore and dolomite from ZG Polkowice cooper mine cored from single blocks have been studied experimentally in uniaxial and triaxial loading conditions. Experiments on dolomite and Wustenzeller sandstone were performed at Rock Mechanics Laboratory at AGH University of Science and Technology with Multi-purpose Rock and Concrete Testing System MTS 815. The experiments on sandstone samples from ZG Rudna were carried out in the Laboratory of Strata Research Institute The Polish Academy of Science with the aid of the strength machine of GTA-10 type (Długosz et al. [8]). Results of these experiments in the context of constitutive model parameters selection and damage variable determination were partially published in the early works (Cieślik [5], [6]).

In this paper, the results of investigations of $26 \mathrm{cy}-$ lindrical samples of Rudna sandstone with dimensions $65 \times 32 \mathrm{~mm}, 18$ cylindrical samples of Wustenzeller sandstone with dimensions $70 \times 35 \mathrm{~mm}$ and 18 cylindrical samples of dolomite with dimensions $70 \times 35 \mathrm{~mm}$ are presented. The experiments were carried out in research series of $1-5$ rock samples for each confining pressure, with the value from 0 to $80 \mathrm{MPa}$ (Figs. 2-4b). In the case of Wustenzeller sandstone and dolomite samples, tests were carried out with loading and un- 
loading path, usually $6-10$ cycles in the pre- and postfailure range (Figs. 3a, 4a). The Rudna sandstone samples characteristics were examined only with loading path (Fig. 2a).

The research was carried out at room temperature and humidity, and the strain rate in all of the experiments was approximately $1 \times 10^{-4}\left[\mathrm{~s}^{-1}\right]$. The measurement of the axial force was carried out by means of a force transducer installed inside the pressure cell while the displacements were measured by extensometers (Cieślik [6]). Radial displacements were determined through the measurement of changes of the sample circumference with a chain put around it, axial ones outside the cell, measuring the piston displacement.

\section{AXIAL SPLITTING, BRITTLE AND DUCTILE BEHAVIOUR OF THE ROCKS INVESTIGATED}

Researches mostly concentrated on the laboratory investigations of rocks behavior (Kwaśniewski [12],

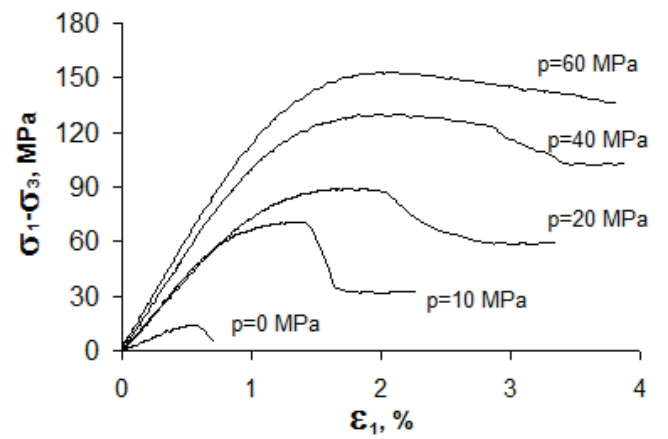

(a)
Gustkiewicz [9], Paterson and Wong [19], Mogi [16]) has shown that depending on the state of stress, rate of loading conditions, humidity and temperature, rocks can display features from brittle, throughout transitional to a ductile state (Fig. 1). Rock samples may fail by axial splitting under uniaxial loading conditions or small value of confining pressures and by shear fracture with single or multiple shear surfaces under triaxial loading conditions. At high confining pressure values, the entire sample undergoes uniform ductile deformations without macroscopically observed shear band formation.
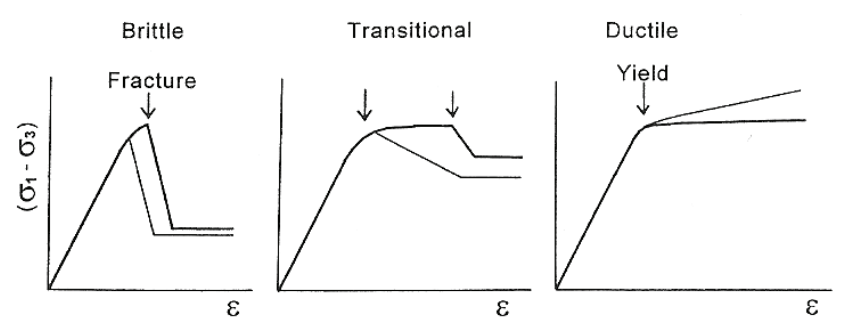

Fig. 1. Schematic representation of transition from brittle state to ductile flow depending on test confining pressure (after Mogi [16])

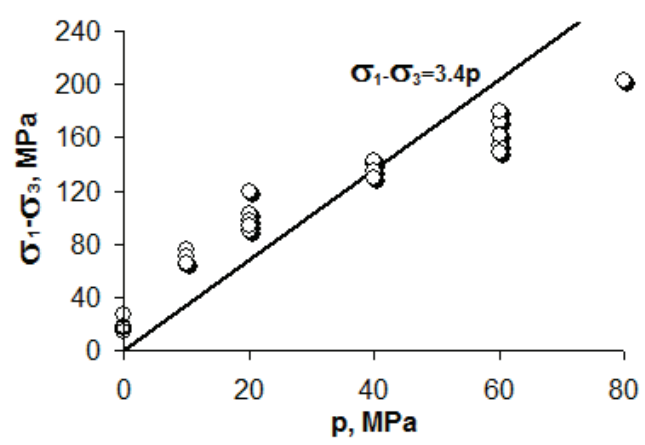

(b)

Fig. 2. (a) Selected characteristics of differential stress-axial strain for Rudna sandstone;

(b) strength versus confining pressure and the failure type for Rudna sandstone

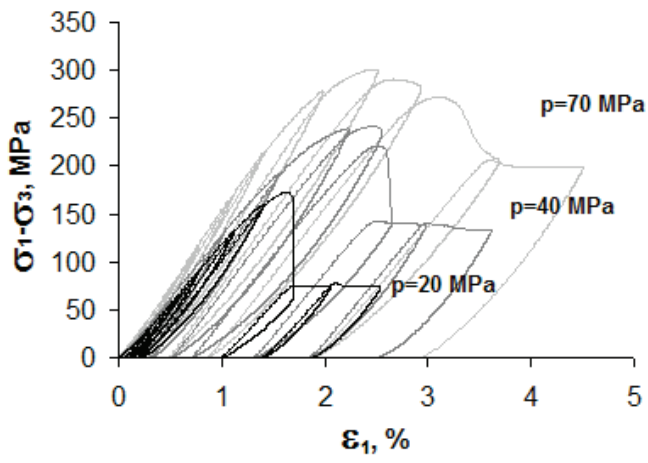

(a)

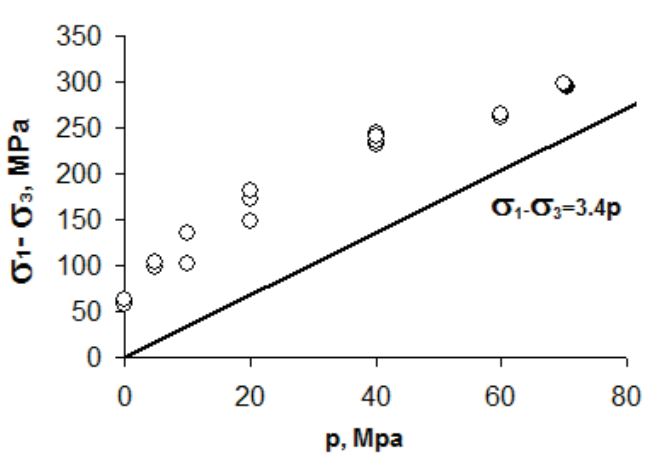

(b)

Fig. 3. (a) Selected characteristics of differential stress-axial strain for Wustenzeller sandstone;

(b) strength versus confining pressure and the failure type for Wustenzeller sandstone 


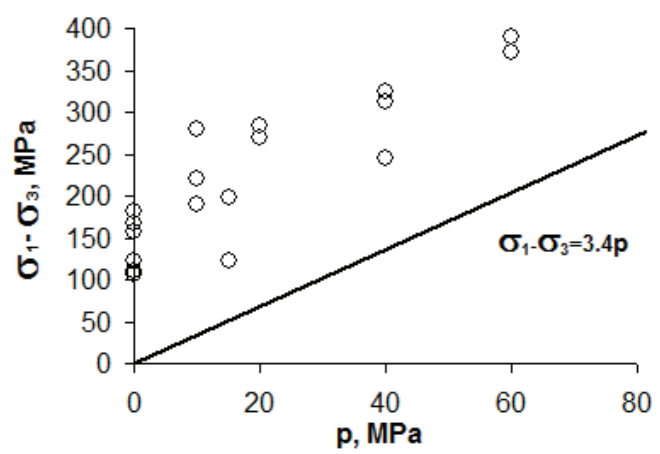

(a)

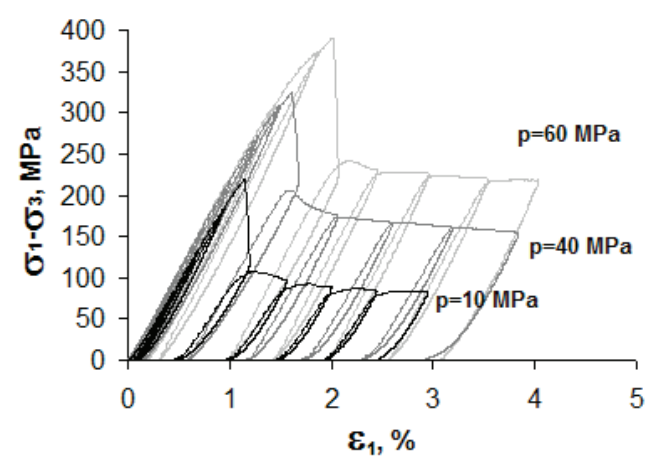

(b)

Fig. 4. (a) Selected characteristics of differential stress-axial strain for dolomite; (b) strength versus confining pressure and the failure type for dolomite

The typical differential stress $\left(\sigma_{1}-\sigma_{3}\right)$ axial strain $\left(\varepsilon_{1}\right)$, characteristics of the rock samples for different confining pressures $(p)$ and their strength versus confining pressure are shown in Figs. 2-4.

On the presented characteristics open circles denote brittle failure, semi-closed transitional one. Analyzing the example, but representative characteristics for all the samples examined, one can easily observe that the rocks behave in a different way.

In the case of Rudna sandstone, from the value of the confining pressure $20 \mathrm{MPa}$ a transitional character of failure was obtained (Fig. 1), between the brittle and ductile one. The samples undergo failure mainly in the form of shear in a single surface or in a group of shear surfaces (for $p=80 \mathrm{MPa}$ and two for $p=60 \mathrm{MPa}$ ). Only in the conditions of uniaxial compression did the failure appear in the form of axial splitting.

The Wustenzeller sandstone samples tested in the whole range of confining pressures, demonstrate a brittle failure except the highest pressure of $70 \mathrm{MPa}$ when the rock sample behaves in transitional state. All the sandstone samples, subjected to triaxial compression undergo failure in the form of a single shear, whereas the ones compressed in the condition of uniaxial loading underwent axial splitting.

Dolomite samples were undergoing the process of brittle failure in all applied confining pressures and the total deformation on the limit strength for all applied confining pressures did not exceed $2 \%$. In the uniaxial tests, failure to the samples occurred in the form of axial splitting.

For all the rock samples softening behavior in the post yield range was observed, which means that the residual stress has a lower value than fracture stress and the ductile behavior and the brittleductile transition phenomenon was not observed.

\section{STRESS DROP ON INTACT ROCK SAMPLES}

In triaxial compression tests carried out on intact rock samples stress drop is defined as a difference between differential stress corresponding to fracture stress and residual stress at advanced loading level (Fig. 1) (Mogi [16]). It is an important parameter of stress-strain characteristic because it provides the energy release that drives failure of rocks.

According to Orowan [17] stress drop is characteristic for brittle failure and does not occur at high confining pressure value corresponding to the threshold of brittle-ductile transition. Brittle-ductile transition determines the pressure at which the frictional resistance on the fault surface becomes higher than the shearing strength of rock (Mogi [15], Byerlee [2]). It was pointed by Paterson and Wong [19] that there is no single mechanism of brittle-ductile transition acceptable for all conditions, and there can be expected a variety in the character of this phenomenon corresponding to the variety of deformation mechanisms in the ductile field. The same conclusion was drawn by Mogi [16], who introduced two types of rock A and B depended on permanent deformation corresponding to the fracture stress. Based on experiments results performed on silicate rocks Mogi [15] proposed a linear criterion for brittle-ductile transition expressed by the equation

$$
\left(\sigma_{1}-\sigma_{3}\right)=3.4 \sigma_{3}
$$

Despite the fact that no britle-ductille transition was observed for all the rock samples, it is clearly visible that criterion proposed by Mogi cannot correspond to this state in the case of Rudna sandstone (Fig. 2b). For Wustenzeller sandstone the tendency of 
the results makes it possible to mach Mogi's line with the brittle-ductile transition (Fig. 3b). For the dolomite samples the confining pressure applied in the experiments was too low for such analysis.

Byerlee [3] based on his experimental results for ten different rocks gave similar conditions for brittleductile transition defined for some ranges of pressure (Lockner [14])

$$
\begin{gathered}
\sigma_{1}=4.7 \sigma_{3} ; \quad \sigma_{3}<114 \quad[\mathrm{MPa}], \\
\sigma_{1}=117+3.1 \sigma_{3} ; \quad 114<\sigma_{3}<1094 \quad[\mathrm{MPa}] .
\end{gathered}
$$

For the experimental result of 62 sandstones Kwaśniewski [13] separated brittle, transitional and ductile state and proposed a nonlinear and linear conditions, respectively

- for a transitional state

$$
\left(\sigma_{1}-\sigma_{3}\right)=8+6.82 p_{T}^{0.815} \quad[\mathrm{MPa}],
$$

- for a ductile state

$$
\left(\sigma_{1}-\sigma_{3}\right)=7.5+1.92 p_{D} \quad[\mathrm{MPa}] .
$$

According to the above, it can be accepted that brittle-ductile transition makes a limit for the stress drop phenomenon in compression experiments. In the works presented by Ismail and Murrel [10] for con- ventional triaxial compression tests the stress drop value is clearly pressure sensitive and it is dependent on test confining pressure. In the case of true triaxial compression (Mogi [16], Kwaśniewski [13]) stress drop is a function of $\sigma_{2}$ and $\sigma_{3}$ respectively. For conventional compression tests stress drop value first rises from the results of uniaxial loading conditions and reaches its maximum with some value of confining pressure, then gradually decreases and disappears for pressure at the brittle-ductile transition. Stress drop values $\left(S_{d}\right)$ versus confining pressure $(p)$ for the sandstones and dolomite under investigation are shown in Fig. 5.

In the results for Rudna sandstone the maximum value of stress drop was observed at confining pressure of $p=20 \mathrm{MPa}$, and after that it decreased to $S_{d}=10 \mathrm{MPa}$ with confining pressure of $p=80 \mathrm{MPa}$. Following the tendency of this results, the brittleductile transition $\left(S_{d}=0 \mathrm{MPa}\right)$ can be matched at pressure near $p=100 \mathrm{MPa}$. The average difference of the stress drop value for uniaxial case and for results at pressure of $p=20 \mathrm{MPa}$ is about $20 \mathrm{MPa}$.

For a Wustenzeller sandstone the greatest value of $S_{d}$ was observed at confining pressure of $p=40 \mathrm{MPa}$, similar as for the dolomite samples. For the sandstone the average difference of the stress drop value for uniaxial case and for results at pressure of $p=40 \mathrm{MPa}$

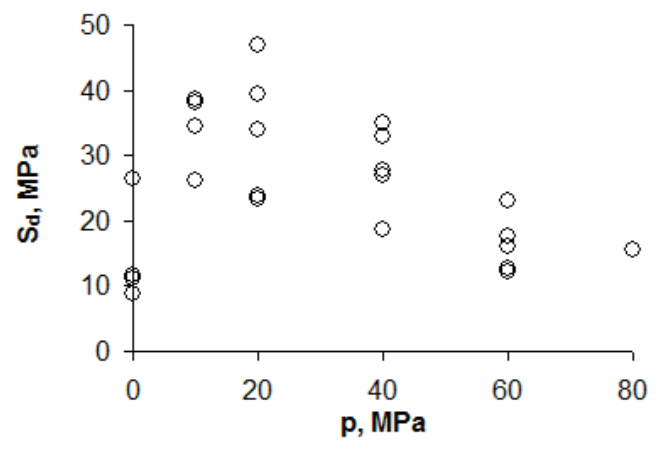

(a)

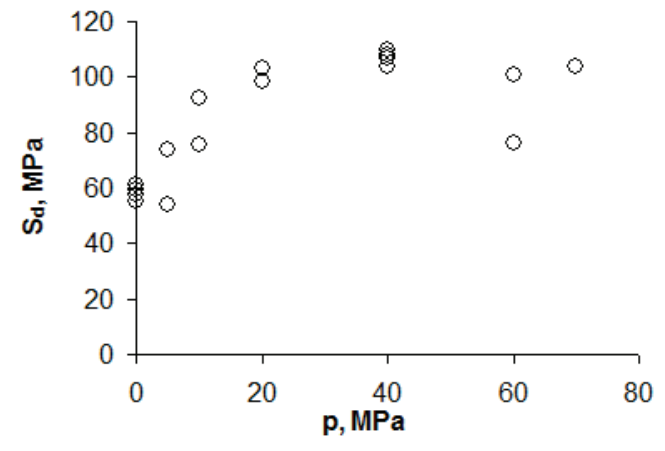

(b)

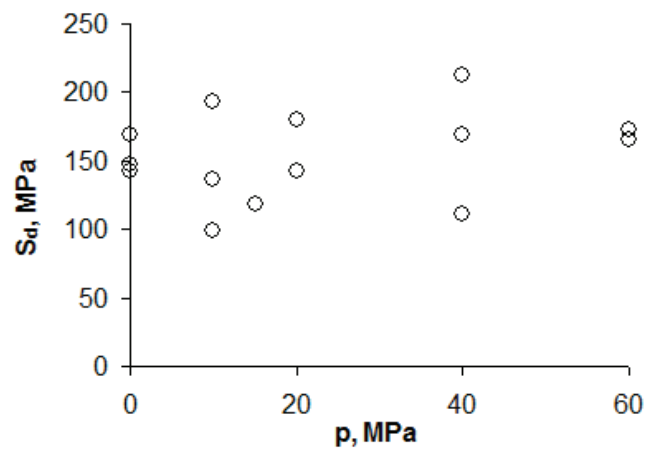

(c)

Fig. 5. Stress drop values for (a) Rudna sandstone, (b) Wustenzeller sandstone, (c) dolomite, evaluated as a difference of fracture and residual stress 
is about $50 \mathrm{MPa}$. The results obtained for dolomite samples were to disperse for evaluation of the stress drop differences.

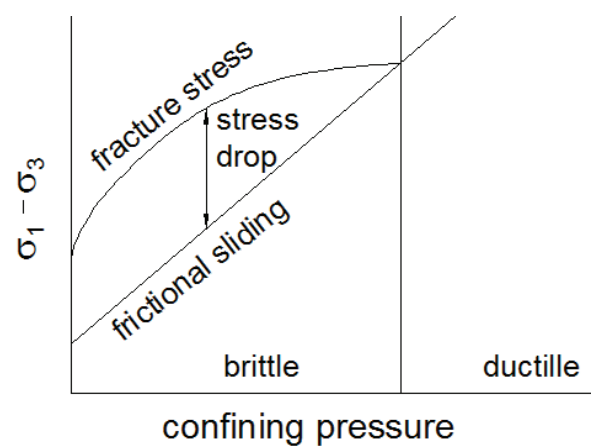

Fig. 6. Schematic relationship for strength versus confining pressure and stress drop definition

In the cases when rocks behave very brittle the data for the post-failure range of the load and residual strength are missing quite often (see Table 1, data for dolomite samples) and the stress drop data consequently are lost, too. According to the definition of stress drop it is possible to obtain its results as a difference of the differential stress at failure to differential stress corresponding to brittle-ductile transition line, Fig. 6 (defining stress for frictional sliding in the shear surface, Fig. 5b), for example, given by Mogi or Kwaśniewski (equations (1), (5)). In that case no data for residual strength are needed. In this paper, the equation defining brittle-ductile transition (equation (5)) proposed by Kwaśniewski was used to obtain a differential stress at shearing resistance and stress drop values for all rocks investigated.

Nonlinear curve defining the transitional behavior (B-T curve, equation (4)) and linear condition for brittle ductile transition (T-D line, equation (5)) fitted with experimental results of sandstones and dolomite are presented in Figs. 7a, 8a, 9a. Results of the calculated stress drop value $\left(S_{d c}\right)$ for T-D line and experimental results of fracture differential stress are shown in Figs. 7b, 8b, 9b.

For the results of Rudna sandstone maximum value of calculated stress drop $S_{d c}$ was observed at confining pressure of $p=20 \mathrm{MPa}$, similar as it was obtained from residual stress. The average difference

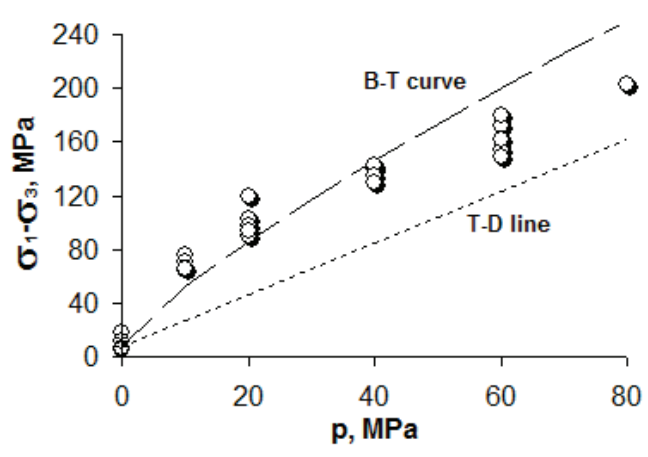

a)

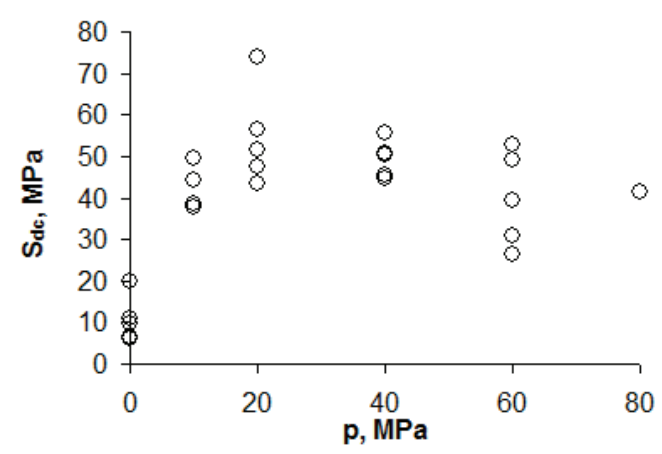

b)

Fig. 7. (a) Brittle-transitional and transitional-ductile conditions (Kwaśniewski [13]) with experimental results of Rudna sandstone; (b) Calculated stress drop values for Rudna sandstone

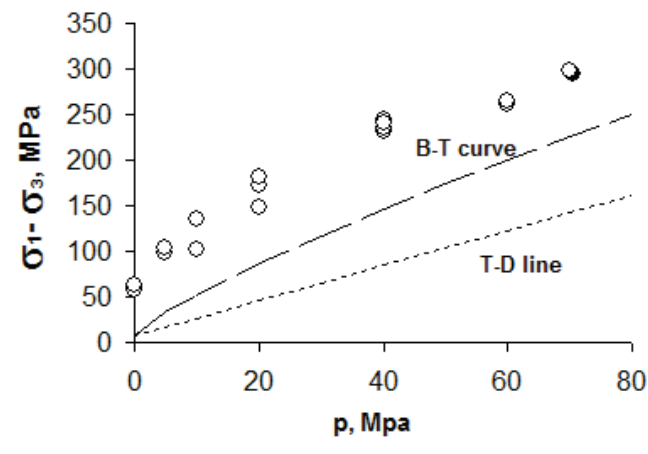

a)

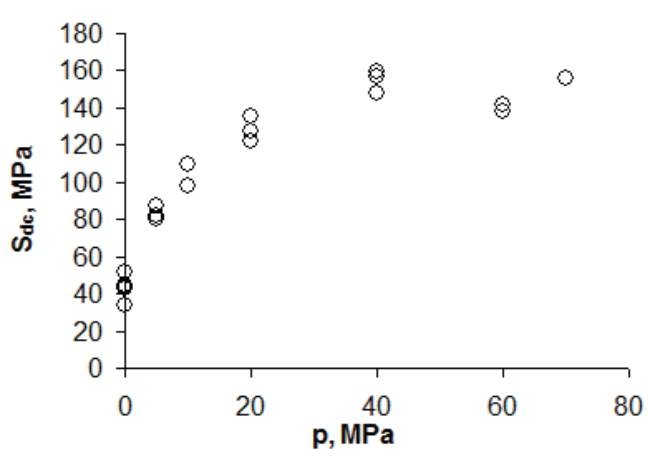

b)

Fig. 8. (a) Brittle-transitional and transitional-ductile conditions (Kwaśniewski [13]) with experimental results of Wustenzeller sandstone; (b) Calculated stress drop values for Wustenzeller sandstone 


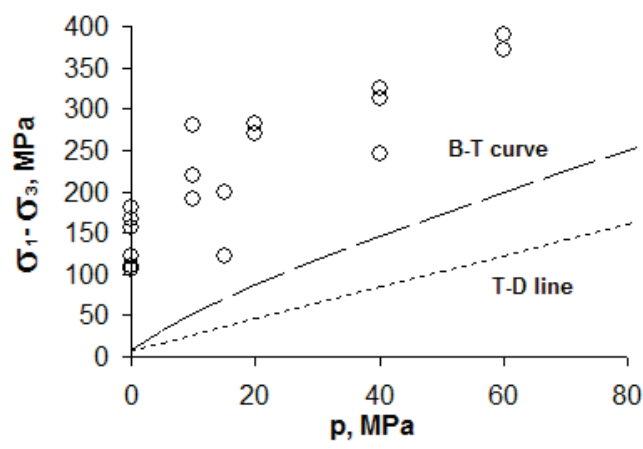

a)

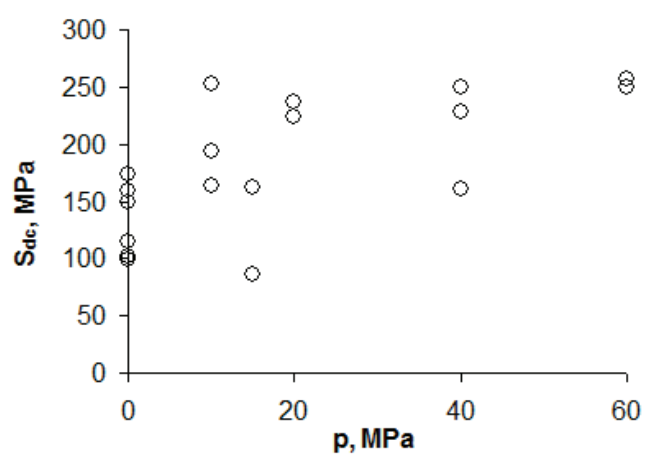

b)

Fig. 9. (a) Brittle-transitional and transitional-ductile conditions (Kwaśniewski [13]) with experimental results of dolomite; (b) Calculated stress drop values for dolomite

between the stress drop value for uniaxial case and for results at $p=20 \mathrm{MPa}$ is about $44 \mathrm{MPa}$. Qualitative comparable results have also been obtained in the case of Wustenzeller sandstone. For this sandstone the average value of calculated stress drop $S_{d c}$ corresponding to confining pressure of $40 \mathrm{MPa}$ was $112 \mathrm{MPa}$.

For the dolomite it can be observed that the stress drop value is rising with test confining pressure exceeding $p=40 \mathrm{MPa}$. When evaluated from residual stress its maximum was obtained for $p=40 \mathrm{MPa}$.

Comparing the presented methods for evaluating stress drop it can be seen that they give results that differ quantitatively but are qualitative similar.

\section{CONCLUSIONS}

Confining pressure applied in mechanical tests strongly influences stress drop phenomenon. Its value first increases and then decreases with confining pressure $p$ rising until it eventually becomes zero. The pressure at with the stress drop goes to zero marks the transition from brittle to ductile state. There can be seen qualitatively similar behavior for very different rock types with very different strengths (Ismail and Murrel [10]).

Stress drop value does not depend on failure mode (axial splitting, shear in single or multi shear band). For the mechanical experiments carried out on two sandstones and dolomite failure mode of rock samples does not influence the stress drop value.

Stress drop value can be evaluated directly from test results of failure and residual stress or partially calculated from failure stress and condition for brittle ductile transition of rock. Both methods give qualitatively similar results.

\section{ACKNOWLEDGEMENT}

This study is sponsored through the statutory research funds of the AGH University of Science and Technology, Faculty of Mining and Geoengineering within the framework of the research program No. 11.11.100.277.

\section{REFERENCES}

[1] Brace W.F., BYerleE J.D., Stick-slip as a mechanism for earthquakes, Science, 1966, 153, 990-992.

[2] ByeRleE J.D., Brittle-ductile transitions in rocks, J. Geophys. Res., 1968, 73, 4741-4750.

[3] ByerleE J.D., Friction of rocks, Pure Appl. Geophys., 1978, $116,615-626$.

[4] ByerleE J.D., Brace W.F., Stick-slip stable sliding and earthquakes - effect of rock type, pressure, strain rate and stiffness, J. Geophys. Res., 1968, 73, 6031-6097.

[5] CIEŚLIK J., Results of triaxial compression tests on LGOM sandstone and dolomite in the context of the elastic-plastic constitutive model selection, Archives of Mining Sciences, 2007, 52 (3), 437-451.

[6] CIEŚLIK J., Scalar damage variable determined in the uniaxial and triaxial compression conditions of sandstone samples, Studia Geotechnica et Mechanica, 2013, 35 (1), 73-84.

[7] DieTERICH J.H., Time dependent friction in rock, J. Geophys. Res., 1972, 77, 3690-3697.

[8] DŁugosz M., Gustkiewicz J., Wysocki A., Apparatus for investigation of rocks in a triaxial state of stress. Part II, Archives of Mining Sciences, 1981, 26, 17-41.

[9] GustKIEwICZ J., Transition of the rocks from the brittle to ductile state. Strain at failure as a function of confining pressure, Acta Geophysica. Polonica, 1985, 33, 169-181.

[10] ISMaIl L.A.H., MurRelL S.A.F., The effect of confining pressure on stress-drop in compressive rock fracture, Technophysics, 1990, 175, 237-248.

[11] JAEGER J.C., COOK N.G.W., Fundamentals of Rock Mechanics, Chapman and Hall, London 1976.

[12] KWAŚNIEWSKI M., The effect of the state of stress, temperature and strain rate on the mechanical properties of rocks, Archives of Mining Sciences, 1986, 31, 384-414, (in Polish). 
[13] KWAŚNIEWSKI M., Behavior of iso- and anisotropic rocks under triaxial compression conditions, Zeszyty Naukowe Politechniki Śląskiej, Górnictwo, nr 1510, (in Polish).

[14] LOCKNER D.A., Rock failure, [in:] AGU Handbook of Physical Constants, ed. Ahrens T.J., Am. Geophys. Union, Washington, D.C. 1995, 3-10, 127-147.

[15] Mogi K., Pressure dependence of rock strength and transition from brittle fracture to ductile flow, Bull. Erthquake Res. Inst., Tokyo Univ., 1966, 44, 215-232.
[16] Mogi K., Experimental Rock Mechanics, Taylor \& Francis, Balkema, 2007.

[17] Orowan E., Mechansm of seismic faulting, Geol. Soc. Am. Mem., 1960, 79, 323-345.

[18] PATERSON M.S., Experimental rock deformation - the brittle field, Springer-Verlag, Berlin, 1978.

[19] PATERSON M.S., WONG T.-F., Experimental rock deformation - the brittle field, second ed., Springer, 2005. 